\title{
"A gente não é de ferro": Vivências de cuidadores familiares sobre o cuidado com idosos dependentes no Brasil
}

\author{
"We are humans after all": Family caregivers' experience of caring \\ for dependent older adults in Brazil
}

\author{
Girliani Silva de Sousa (https://orcid.org/0000-0002-0988-5744) ${ }^{1}$ \\ Raimunda Magalhães da Silva (https://orcid.org/0000-0001-5353-7520) ${ }^{2}$ \\ Amanda Márcia dos Santos Reinaldo (https://orcid.org/0000-0003-0283-2313) ${ }^{3}$ \\ Sônia Maria Soares (https://orcid.org/0000-0003-3161-717X) ${ }^{3}$ \\ Denise Machado Duran Gutierrez (https://orcid.org/0000-0002-0031-3045) ${ }^{4}$ \\ Maria do Livramento Fortes Figueiredo (https://orcid.org/0000-0003-4938-2807) ${ }^{5}$
}

\footnotetext{
${ }^{1}$ Departamento de Enfermagem Clínica e

Cirúrgica, Escola Paulista de Enfermagem, Universidade Federal de São Paulo. R. Napoleão de Barros 754, Vila Clementino. 04024002 São Paulo SP Brasil. girlianis@gmail.com ${ }^{2}$ Programa de PósGraduação em Saúde Coletiva e de Enfermagem, Universidade de Fortaleza.

Fortaleza CE Brasil. ${ }^{3}$ Escola de Enfermagem, Universidade Federal de Minas Gerais. Belo Horizonte MG Brasil. ${ }^{4}$ Programa de PósGraduação Mestrado Acadêmico em Psicologia, Universidade Federal de Amazonas. Manaus AM Brasil.

${ }^{5}$ Programa de PósGraduação em Enfermagem, Universidade Federal do Piauí. Teresina PI Brasil.
}

\begin{abstract}
This paper aims to understand the experiences of family caregivers with dependent older adults in Brazil and the consequences of $\mathrm{ca}$ ring for dependent older adults in the family caregiver's life. This is a qualitative multicenter study employing dialectical hermeneutics as a theoretical framework. In-depth interviews were conducted with 84 family caregivers in Brasilia, Rio de Janeiro, Belo Horizonte, Fortaleza, Teresina, Porto Alegre, and Araranguá, and Manaus. The thematic analysis yielded three categories: motivations for taking on the caregiving role, influences on the family caregiver's life, coping, and self-care modalities. The care assumed is influenced by affective relationships with older adults and ethical and moral responsibilities. The influences are related to the lack of preparation for caregiving, financial hardship, restricted freedom, and physical and mental health problems. Coping strategies were religion, spirituality, turn-taking between family caregivers, and learning about the tasks. Women predominate in caregiving due to cultural, ethical, and moral reasons. However, family caregivers often lack guidance and require protection and a support network.
\end{abstract}

Key words Family caregivers, Frail older adults, Care, Qualitative research
Resumo O artigo visa compreender a vivência dos(as) cuidadores(as) familiares com a pessoa idosa dependente no Brasil, bem como entender as consequências dos cuidados de idosos dependentes na vida do cuidador familiar. Estudo multicêntrico, de caráter qualitativo, com referencial teórico hermenêutico-dialético. Foram realizadas entrevistas em profundidade com 84 cuidadores familiares nas cidades de Brasília, Rio de Janeiro, Belo Horizonte, Fortaleza, Teresina, Porto Alegre, Araranguá e Manaus. Da análise temática, emergiram três categorias: motivações para assumir o papel de cuidador; influências na vida do cuidador familiar; e modalidades de enfrentamento e de cuidado de si. O cuidado assumido é influenciado pelas relações afetivas com o idoso e pela responsabilidade ética e, também, moral. As influências dizem respeito a despreparo para o cuidado, difculdades financeiras, cerceamento da liberdade $e$ problemas de saúde física e mental. A religião, a espiritualidade, a alternância entre os cuidadores familiares no cuidado e o aprendizado sobre essas tarefas foram estratégias de enfrentamento. A mulher predomina no ato de cuidar por motivações culturais, éticas e morais. Mas frequentemente falta orientação aos cuidadores familiares, que precisam de uma rede de apoio e proteção.

Palavras-chave Cuidadores familiares, Idoso fragilizado, Cuidado, Pesquisa qualitativa 


\section{Introdução}

O aumento da longevidade passou a exigir maior necessidade de cuidado com os idosos. No Brasil, ocorre uma demanda crescente que recai sobre a família que, tradicionalmente, oferece a assistência necessária aos idosos que não conseguem realizar as atividades de vida diária ${ }^{1}$. Isto acontece, como um fenômeno cultural que se agudiza no contexto socioeconômico das famílias que residem em localidades com baixo Índice de Desenvolvimento Humano (IDH) ${ }^{2}$.

O desafio do cuidado do idoso impõe à família o dilema de conciliar e reordenar as demandas do cotidiano do cuidado e as outras tarefas domésticas, sociais e profissionais.

O grupo familiar é um elo vital na prestação de cuidados para idosos dependentes com múltiplas condições crônicas. Estudos quantitativos nacionais e internacionais têm encontrado menor qualidade de vida, problemas de saúde física e mental - como lombalgia, varizes, hipertensão, diminuição do sono, sintomas depressivos e ansiosos - em cuidadores familiares ${ }^{2-7}$. Eles também expressaram maiores níveis de tensões e de sobrecarga, associados às dificuldades para executar as atividades básicas e instrumentais da vida diária e a rotina de cuidados exigida ${ }^{2,7}$.

Pesquisas qualitativas e revisões mais recentes advogam a ideia de que, apesar do ônus das rotinas de cuidado, as motivações e a intersubjetividade das relações familiares com os idosos influenciam positivamente na adaptação e no enfrentamento da situação de assisti-los ${ }^{8-11}$.

Nessa linha de pensamento, este artigo apresenta uma experiência de ouvir os cuidadores familiares e tem como objetivo compreender a vivência dos(as) cuidadores(as) familiares com a pessoa idosa dependente no Brasil, bem como entender as consequências dos cuidados de idosos dependentes na vida do cuidador familiar. O enfoque nos membros familiares que cuidam da pessoa idosa dependente é fundamental para direcionar o planejamento do suporte dos serviços de saúde para garantir que os cuidadores familiares não se sintam abandonados.

O estudo se justifica pela invisibilidade do tema nas políticas públicas, dentro do pressuposto de que a família sozinha não deve arcar com o ônus de cuidar de seu ente querido dependente, devendo ser compartilhado entre a família, o Estado e a sociedade civil. Essa responsabilidade que precisa ser assumida e liderada pelo poder público já ocorre em vários países do mundo ${ }^{3,12}$ como uma política de Estado e faz falta no Brasil, particularmente numa realidade de desigualdade social.

\section{Método}

A pesquisa teve o objetivo de realizar um estudo qualitativo sobre a situação dos idosos dependentes que vivem com suas famílias, e de seus cuidadores, com o intuito de subsidiar propostas para uma "Política sobre a Dependência" no Brasil. Ela foi aprovada pelo Comitê de Ética de Pesquisa da Fundação Oswaldo Cruz. Neste artigo, o cuidador familiar é o foco.

Por meio de abordagem qualitativa, procurou-se investigar os sentidos que os membros familiares responsáveis pelo idoso dependente atribuem a vivências, vínculos e dinâmica familiar no seu exercício cotidiano de cuidado. Considerou-se o referencial teórico-metodológico hermenêutico-dialético como o mais adequado para guiar as entrevistas em profundidade com os cuidadores familiares. Ou seja, partiu-se do pressuposto de que as falas devem ser compreendidas no contexto em que são produzidas. Mas, ao mesmo tempo elas se situam em conjunturas concretas, numa cultura que ultrapassa e inclui essas pessoas, tornando-as parte de um movimento histórico e simbólico da atualidade ${ }^{1,13,14}$, dando conta das mesmas questões aqui tratadas localmente, com reflexão e crítica ${ }^{15}$. Os instrumentos de pesquisa permitiram aos pesquisadores conversar com os entrevistados sobre as relações entre os familiares e os idosos, suas opiniões sobre a dependência e como vivem, pensam e elaboram os modos de cuidar.

$\mathrm{O}$ estudo envolveu municípios de cinco regiões do Brasil: do Centro-Oeste, Brasília; do Nordeste, Teresina e Fortaleza; do Norte, Manaus; do Sudeste, Rio de Janeiro e Belo Horizonte; e do Sul, Porto Alegre e Araranguá. A escolha das cidades se deu na intenção de ampliar o conhecimento sobre cuidadores familiares de idosos dependentes no país, em distintos contextos de vida e de cultura.

$\mathrm{O}$ acesso aos participantes foi intencional e aconteceu pela mediação de agentes comunitários de saúde; indicação de geriatras dos serviços especializados e indicação de parentes. Os 84 cuidadores familiares de idosos dependentes contatados e que aceitaram participar do estudo foram entrevistados no domicílio, no período de junho a setembro de 2019. O número de participantes foi determinado pelo caráter de saturação dos dados, ou seja, quando se observou regularidades 
nas informações e reincidência temática aos objetivos do presente estudo.

Observaram-se os critérios de: serem familiares cuidadores dos idosos dependentes e estarem presentes no momento da entrevista. Excluíramse os familiares de idosos institucionalizados e os parentes que não cuidavam diretamente do idoso.

Com os participantes, foram agendados data, horário e local para as entrevistas, conduzidas por pesquisadores com formação superior na área da saúde e em ciências humanas, experiência na temática sob exame e que tivessem feito o treinamento para o uso do manual de instruções do estudo. As "conversas com finalidade" 15 ocorreram individualmente, na casa do participante, em local reservado, livre de ruídos, com duração média de 60 minutos. O Termo de Consentimento Livre e Esclarecido (TCLE) foi lido, tendo sido, ainda, solicitada autorização para gravar as conversas e assegurado o respeito às histórias contadas pelos participantes, sem julgamento ou críticas.

Para criar um clima harmonioso e de confiança entre entrevistador e entrevistado, explicou-se à pessoa interlocutora a importância da pesquisa, pois a intenção é subsidiar a elaboração de uma política específica sobre a "Dependência no Envelhecimento" que melhore as condições de trabalho e de saúde dos cuidadores.

As entrevistas foram transcritas na íntegra, seguida de organização dos dados em um corpus analítico. Nessa lógica, as inferências compreensivas e interpretativas dos pesquisadores, por meio da leitura do material empírico, permitiram ter uma visão geral de conjunto e apreensão das particularidades dos contextos da realidade em que se inserem os participantes e de seus ambientes socioculturais, identificando-se os temas sobre motivações para assumir o papel de cuidador, influências na vida do cuidador familiar e modalidades de enfrentamento e de cuidado de si. A análise dessas categorias se deu pelos pressupostos da compreensão e da crítica, com apoio da literatura nacional e internacional.

Para garantir seu anonimato, os participantes foram identificados pelas letras iniciais de seus nomes civis, idade, estado civil, sexo, tempo como cuidador e município onde reside.

\section{Resultados e discussão}

\section{Informações gerais}

Dos cuidadores familiares entrevistados, 71 $(88,7 \%)$ são do sexo feminino e $13(11,3 \%)$ do masculino. Desse conjunto, sete $(8,3 \%)$ tinham de 20 a 39 anos; 44 (52,3\%) estavam na faixa etária de 40 a 59 anos; $12(14,3 \%)$ estavam no grupo de 60 a 79 anos; e $21(25,1 \%)$ tinham acima de 80 anos. Do total de cuidadores, 39 (46,4\%) eram filhas ou filhos; 25 (29,8\%), outros familiares, como irmãs, sobrinhas e netas; e 20 (23,8\%) eram esposas ou esposos.

Observou-se que $44(52,38 \%)$ das pessoas exerciam o cuidado por dois a cinco anos; oito (9,5\%) de seis a nove anos; 22 (26,2\%) há mais de dez anos; e dez $(9,5 \%)$ há menos de um ano. Do total, 46 (54,8\%) dos participantes não contavam com mais ninguém para assistir à pessoa idosa.

\section{Motivações para assumir o papel de cuidador}

As motivações alegadas pelas pessoas para a decisão de assumir o cuidado envolvem diversos aspectos. Existem as focadas na ética da reciprocidade, nos sentimentos de gratidão, afeto, admiração e amor pela pessoa idosa; as que se sustentam pelos vínculos afetivos e harmoniosos, estabelecidos no decorrer da existência; e as que decorrem da falta de opção entre os membros familiares para assumir o cuidado e pela responsabilidade moral e ética para não abandonar a pessoa idosa. Registram-se relacionamentos com pais, mães e filhas e filhos; matrimoniais; fraternos e, em alguns casos, de sobrinhas, netas, noras e até de ex-esposas. Segundo uma filha-cuidadora, sua motivação se baseia no afeto.

Por tudo que ela fez por mim. Quando eu nasci, eu tinha que ter certos cuidados mais especiais, ela foi uma mãe muito cuidadosa depois que soube do caso [nanismo]. Não é só por isso, é o amor. O que me faz estar com ela não é nem pela doença, é o amor. (RMRC, 51 anos, solteira, cuida da mãe há um ano, Rio de Janeiro).

Os relatos explicitam a responsabilidade moral e ética para assumirem o cuidado. As lembranças do tempo que os idosos dedicaram à família, seu afeto e suas histórias de sacrifícios e renúncias para criarem e educarem os filhos são os motivos mais rememorados. Os filhos sentem, portanto, dever e obrigação de cuidar e apoiar os pais durante o envelhecimento. Relatam reciprocidade pelo cuidado recebido e se veem sendo gratos pela oportunidade de cuidar. Estudo na Tailândia com cuidadores familiares constatou que o cuidado está associado a sentimentos de responsabilidade, gratidão e piedade ${ }^{16}$. Outro estudo aponta como razão do cuidado, as relações familiares de longa data, seja por sangue ou casamento ${ }^{17}$. 
Maridos e esposas assumiram o cuidado diante de determinadas circunstâncias, como: filhos residentes em outros municípios, ou que possuem suas próprias famílias e não querem sobrecarregá-los. Também foi apontado como razão do cuidado, o casamento marcado pelo relacionamento amoroso, forte e duradouro, em que reside um engajamento genuíno em relação ao outro.

Por todos os anos que passamos juntos, prometi cuidar para sempre dela. Cuido com muito zelo, afeto, carinho e preocupação, não vejo como obrigação, sei que não é algo que ela escolheu e ela sempre foi uma pessoa tão maravilhosa que eu cuido com muito amor e dedicação (CCA, 81 anos, esposo cuida da esposa há quatorze anos, Brasília)

O marido ao receber o diagnóstico de mal de Alzheimer da esposa, assumiu a função de cuidador em tempo integral, criou uma rotina de cuidados capaz de compreender e anotar os mínimos sinais que a idosa manifesta para relatar ao médico. Resultados semelhantes foram encontrados no Chile ${ }^{18}$, onde estudiosos chamam atenção para o fato de que o próprio cuidador prioriza o atendimento das necessidades básicas da vida diária do seu ser querido, o que, muitas vezes, acaba por limitar o exercício do seu autocuidado.

$\mathrm{O}$ respeito pela história vivida com a pessoa idosa no casamento também se constitui em um imperativo para o cuidado mesmo nos casos em que os relacionamentos com os idosos tenham sido rompidos anteriormente a seu adoecimento, como sucede com ex-esposas.

Eu cuido porque ele é o pai da minha filha, por mais que houve desavença, eu não o deixaria passar falta de nada. Eu voltei para casa para ajudar a cuidar da mãe dele e dele, eu cuidei da mãe dele, aí ele teve o AVC, passei a cuidar dele (AGJ, 60 anos, divorciada, cuida do ex-marido há doze anos, Belo Horizonte).

As ex-esposas explicitaram que apesar de terem tido casamentos permeados por violências, traições e conflitos voltaram a cuidar do idoso pelo fato deles não terem outros membros familiares que assumissem o cuidado. A situação fez emergir o sentimento de piedade e respeito pelos anos anteriores de convivência. Esses idosos haviam migrado da zona rural para a urbana, o que fez com que perdessem o contato com os familiares da família extensa. Essa circunstância também esteve presente em uma ex-nora que cuida do ex-sogro por receio dele ser abandonado pela família.

$\mathrm{Na}$ pesquisa, foram encontradas situações de resistência dos familiares em cuidar, em especial com famílias numerosas; conflitos em dividir as tarefas diante da dependência da pessoa idosa; $\mathrm{e}$ sobrecarga das mulheres.

Ah, sinceramente? Todo mundo caiu fora, a responsabilidade mais é comigo. Eu cuido, dou amor, dou carinho. Ela ficou viúva com trinta e nove anos, ela podia ter vivido a vida dela, casado, ter tido outros filhos, ter outra vida e ela viveu só para os filhos, a gente tem que retribuir, ela não cobrou da gente, eu acho que moralmente é nosso dever (ARS, 49 anos, casada, filha cuida da mãe há três anos, Belo Horizonte).

No relato acima, com a proximidade da alta hospitalar da idosa, os seis filhos se reuniram e optaram pela institucionalização. Entretanto, uma das filhas assumiu o cuidado da mãe, pois $o$ sofrimento dela me incomoda mais do que minha própria vida. Aqui fica evidente que as dimensões de afeto e emocionais influenciam na decisão de assumir o cuidado com o idoso. Nesse caso concreto, ele foi observado em outros países, quanto ao cuidado assumido por apenas um familiar ${ }^{19-21}$.

Notou-se que os cuidadores familiares se sentem envergonhados em verbalizar que exercem o cuidado por falta de opção e nem sempre falam abertamente sobre a disfuncionalidade familiar. Os conflitos familiares que ocorrem entre os membros da família para não compartilhar o papel de cuidador geralmente estão associados ao quanto é penoso, oneroso e atrapalha a vida de quem cuida ${ }^{5,6,6,11,13}$. É nesse ensejo que surge o componente da família que assume a função de modo solidário, solitário, por devoção e pelo dever de responsabilidade, cumprindo assim a tradição dos países de cultura latina, em que os filhos adultos são responsáveis pelos pais quando estes envelhecem ${ }^{11,19,22}$. Outros grupos étnicos, como os orientais, também mantêm a cultura dos membros da família cuidarem uns dos ou$\operatorname{tros}^{17,22,23}$. No Brasil, a ausência do poder públi$\mathrm{co}^{19}$ pesa sobre o cuidador familiar.

Destaca-se o fato da maioria dos cuidadores familiares ser composta por mulheres. O papel de cuidadora familiar aparece como uma sina:

Eu acho que na cultura brasileira, a mulher sempre foi a que cuidou da casa, a que esteve perto, tem mais senso de responsabilidade e de ficar e de cuidar dos pais. [...] Nós mulheres fomos criadas para cuidar da prole e quando nós temos nossos pais, nossos pais viram nossos filhos, o homem casa, ele vai cuidar da e se dedicar a família deles (LMP, 58 anos, filha cuida do pai há cinco meses, Porto Alegre).

Identifica-se nessa fala os papéis tradicionais de gênero que incluem a manutenção do lar, do 
casamento e o cuidado aos pais e aos filhos enraizados na sociedade contemporânea ${ }^{17,19,22}$. A tarefa de cuidar de idosos recai sobre esposas, filhas, noras, sobrinhas e netas. No Canadá ${ }^{24}$ e nos países europeus ${ }^{21,25}$, a luta dos cuidadores e cuidadoras familiares é por reconhecimento social e apoio econômico do Estado para o cumprimento de sua função $0^{5,26}$. Nos relatos da pesquisa, essas questões não foram levantadas. O documento da Oxfam ${ }^{13}$ lançado na Reunião de Doha denunciou a invisibilidade do trabalho das mulheres cuidadoras em todo o mundo, trabalho que as empobrece financeiramente e enriquece o mundo capitalista e patriarcal.

Neste estudo, no mesmo sentido dos argumentos anteriores aponta-se que os homens não são a primeira opção para assumir os cuidados. Eles o fazem quando não há alternativa:

Eu fiquei uns tempos fora, minha irmã e a minha sobrinha cuidavam, mas a minha sobrinha arrumou filho e minha irmã estava chegando muito tarde. Eu saí do serviço em que eu trabalhava à noite para ficar em casa e vou ficar até quando Deus quiser cuidando dela (RNM, 40 anos, solteiro, filho cuida da mãe há três anos, Belo Horizonte).

Neste estudo, foram identificados filhos solteiros e esposos cuidando de idosas. A dedicação integral dos homens aos cuidados costuma ser motivada pela circunstância de eles serem solteiros, pois, quando casados, em geral, são as noras que assumem a responsabilidade. Em relação aos maridos, estudo na Alemanha ${ }^{27}$ considera que a situação de homens cuidando de suas esposas não pode ser generalizada para todas as faixas etárias. Na velhice, o cuidado ofertado por eles costuma ocorrer quando já se retiraram do mercado de trabalho ${ }^{27}$.

Os homens que cuidam tendem a receber mais ajuda externa nas tarefas domésticas, o que é referendado por um estudo longitudinal na Alemanha ${ }^{27}$. Nele se encontrou que os cuidadores homens têm uma probabilidade significativamente maior de receber apoio externo $(29,6 \%)$ em comparação com as mulheres $(17,7 \%)^{27}$.

\section{Influências na vida do cuidador familiar}

As mudanças na vida dos cuidadores quando enfrentam uma situação inesperada de dependência de um membro da família são muito grandes e, em geral, despertam preocupação com as dificuldades que enfrentarão, com sua inexperiência e com a imprevisibilidade da situação:

O serviço de saúde poderia melhorar com disponibilização de medicamentos prioritários para o idoso e que as clinicas geriátricas do SUS tivessem capacitação e orientação para os cuidadores, o começo é muito difícil, tem muito insegurança sobre o que fazer, como fazer. Antes em Brasília, junto com a consulta com o idoso, o cuidador também passava pelo clínico geral e isso era ótimo, pois muitos cuidadores não conseguem se tratar. O idoso e o cuidador deveriam ser tratados com mais respeito e dignidade (MVL, 45 anos, cuida do pai com Parkinson há seis anos, Brasília).

A insegurança em lidar com esse novo contexto e os limites do cuidado são questões comuns entre os entrevistados em todos os municípios pesquisados. Praticamente todos falam da necessidade de aprendizado sobre o envelhecimento e a doença que tornou seu familiar dependente, a fim de compreender suas mudanças comportamentais e ofertar-lhes bem-estar e satisfação.

Essas circunstâncias podem aumentar a sobrecarga dos que assistem e ensejar sentimentos de angústia e estresse $\mathrm{e}^{10,16,18}$. A ausência de suporte educacional e de treinamento para ajudar, principalmente nos estádios iniciais do cuidado, pode perdurar por longo prazo, particularmente se há comorbidades e sintomas complexos, muitas vezes, imprevisíveis ${ }^{8-10,16,21}$. Todos os casos ouvidos indicam a necessidade de promover atenção ao cuidador familiar, com um cuidado especial centrado na pessoa, em que se leve em consideração as particularidades dos idosos e de quem os assiste $^{3,8,19}$.

Encontrou-se que a maioria dos cuidadores familiares manifesta seu desejo em assumir o protagonismo para assistir a pessoa idosa. Esse é mais um motivo para que se estabeleçam vínculos com os profissionais de saúde para um cuidado mais adequado e efetivo. Com efeito, a valorização do cuidador familiar pode facilitar o manejo clínico e as condutas assertivas dos profissionais que passam a ter um melhor entendimento das situações. Entende-se que o trabalho colaborativo pode reduzir o estresse do cuidador familiar e aliviar os serviços de atenção, pois, ao se sentir valorizado, ele é implicado no cuidado $^{10,19,20}$. Há hoje a tendência de considerar o trabalho de cuidadoras e cuidadores familiares como parte integrante dos sistemas de saúde ${ }^{21,24}$.

Os participantes consideraram como a parte mais difícil conciliar os cuidados de sua saúde com as demandas de cuidado à pessoa idosa. Esses achados se intensificam quando não há alternância do cuidado ou nos casos em que a pessoa idosa precisa de cuidados intermitentes. Em consequência, a pessoa que cuida se vê obrigada a sacrificar várias dimensões de sua vida, dando 
ensejo a repercussões negativas em sua saúde física e mental:

Ganhei um tanto de xingo semana passada, no médico, porque têm dois anos que eu não tomo nenhum remédio. Eu parei um tempo, quando minha mãe estava internada, e quando minha mãe desequilibra, não pode sair de perto dela. Como que eu ia tomar um remédio de pressão que faz a gente fazer muito xixi? Não tinha jeito. Eu ia tomar a fluoxetina, que faz a gente dormir, ficar tranquila. Eu não podia. Eu tinha que estar sempre acesa (GPRD, 55 anos, viúva, cuida da mãe há seis anos, Belo Horizonte).

Outros cuidadores que cuidam sozinhos falaram a respeito de sua situação de forma semelhante, pontuando que as demandas de seus entes os levam à exaustão física e mental e à privação da liberdade. São pessoas que precisam conciliar o cuidado com outras tarefas. Um estudo com mulheres mexicanas cuidadoras expressam as mesmas sensações de cansaço, esgotamento e sobrecarga ${ }^{11}$.

A rotina de cuidados é demasiadamente cansativa, sobretudo, para as pessoas que precisam assistir o familiar diuturnamente, levando-as ao estresse emocional ${ }^{3}$, e, por vezes, à síndrome de burnout. Esse último caso ocorre, principalmente, com os cuidadores familiares de idosos com demência ${ }^{2,7,8}$.

O tempo dispensado para o cuidado com o idoso, somado à falta de espaço para realizar as atividades de cunho pessoal sobrecarrega o cuidador, pois existe uma relação clara entre maior dependência do idoso, tempo despendido para o cuidado direto e menor tempo para si. Esse dado evidencia a necessidade de dar visibilidade ao problema e promover formas de dividir e reorganizar as atividades de cuidado, buscando o equilíbrio e o bem-estar do cuidador ${ }^{3,19}$.

Estudo na Espanha comprovou que 39\% dos cuidadores possuíam sintomas depressivos ${ }^{22}$. A obrigação familiar de cuidar sozinhos e os pensamentos disfuncionais sobre essa responsabilidade agem de modo indireto na sintomatologia depressiva $^{22,28}$. As repercussões psicossociais negativas nos componentes familiares são maiores quando eles creem que não estão conseguindo ofertar o cuidado como deveria ser feito ${ }^{22,28}$.

A ausência de uma rede sociofamiliar para o compartilhamento do cuidado na dependência interfere na experiência do cuidador familiar que vivencia as atividades da vida diária com cansaço físico, mental e dificuldades financeiras. Nesse contexto, a filha cuidadora reconhece:

Eu vou ficando estressada, cansada também, às vezes eu me sinto injustiçada, eu acho que uma pessoa "pira" com tudo, às vezes enche e o que cansa não é só o cuidar, dar comida e banho, eu acho pior é lidar com o comportamento dela, o estresse maior é o humor. Eu estou perdendo a facilidade de sorrir, isso me afeta, sinto falta de trabalhar, de viver, ter tempo e com a falta de dinheiro agrava ainda mais (CRS, 50 anos, filha cuida da mãe com Alzheimer há nove anos, Fortaleza).

Para alguns participantes lidar sozinhos com as alterações de humor da pessoa idosa os levou ao esgotamento mental ${ }^{2,7,8,22,28}$ em que se exauriu a habilidade de lidar com paciência, dando margem para as contradições, conflitos e tensões no papel de cuidador. Pesam sobre as necessidades cotidianas do cuidador familiar, o desejo de trabalhar, de ter momentos de liberdade e melhores condições financeiras.

Heidegger $^{29}$ sinaliza que é preciso perceber que as pessoas que cuidam se arriscam, possuem limitações, erram e acertam, e precisam de cuidado para cuidar do outro. Não se pode cuidar sem considerar as determinações ontológicas da condição humana, a identidade própria do humano que é construído na coexistência e na inter-relação que neste estudo revela as limitações do cuidado com dedicação e inquietação pelo outro. $\mathrm{O}$ cuidado só é autêntico quando unifica realidade e possibilidade, mas uma possibilidade enquanto condição humana que leva em consideração os comportamentos e atitudes do ser humano.

Foram encontrados casos de homens e mulheres jovens e economicamente ativos que tiveram de deixar a atividade laboral para cuidar do idoso familiar. Em outras situações, os familiares assumiram o cuidado por estarem desempregados e comentam que ficaram impossibilitados de retornar ao mercado de trabalho por não encontrar na família ou no poder público nenhuma alternativa. Apenas em uma família, os irmãos concordaram em pagar o salário mínimo da irmã que cuida, reconhecendo socialmente o trabalho desempenhado por ela. Em sua maioria, os cuidadores então passam a depender de suas famílias para cobrirem as despesas pessoais e com o idoso. Essa tensão de viés econômico também tem sido encontrada em outros países ${ }^{6,9,10}$.

Para alguns há ainda os desafios para conciliar o trabalho profissional com as demandas de cuidado: Eu tenho que aprender a separar porque senão eu vou me dar mal no meu trabalho (RMRC, 51 anos, solteira, cuida da mãe há um ano, Rio de Janeiro). Essa realidade é semelhante em outros países e em alguns deles, como na Alemanha ${ }^{5,27}$, na política a favor da pessoa dependente estão previstos arranjos de horário, tempo e flexibili- 
zação de salário que facilitam os cuidados. Dos entrevistados desta pesquisa, muitos cuidadores ocupavam cargos importantes nas organizações ${ }^{6}$ e não conseguiram abrir mão do emprego, apontam que mesmo tendo alguém em casa, a preocupação com os medicamentos, a alimentação e outras tarefas relativas ao ente querido, significa cansaço para conciliar com as demandas ocupacionais $^{2,6,8}$.

Em face dessa situação, programas de cuidadores de idosos são disponíveis pelos governos canadense e dinamarquês para proporcionar ao cuidador familiar tempo para conciliar o trabalho, e outras atividades ${ }^{5,10,30}$. É uma alternativa viável para quem não pode ou não quer custear cuidadores formais.

\section{Modalidades de enfrentamento e de cuidado de si}

A maioria dos cuidadores considera que, para ter um pouco de controle sobre sua vida pessoal, precisam de ajuda: uma rede de apoio que lhes permita cuidar de si; alguém com quem possa compartilhar seus sentimentos, sem julgamento nem críticas; estar conectado física e mentalmente com os outros ${ }^{11}$, aprender sobre o adoecimento do ente e a presença da religião e da fé.

Dentre as estratégias de apoio, na pesquisa foi citada a busca de ajuda dentro da família para alternância na função: A gente não é de ferro e eu me canso, mas se eu precisar ir ao médico eu vou e minha irmã fica lá, uma ajuda a outra e eu acabo desabafando com ela muitas coisas, muita conversa, passo o dia conversando (JMA., 54 anos, nora cuida do idoso há dois anos, Manaus). Essa alternância também foi mencionada por outros cuidadores, que citaram a necessidade de ter momentos prazerosos, de lazer, viagens e passeios, dando um pouco de leveza em sua vida e o necessário cuidado de si:

Quando eu quero sair eu saio, passeio e viajo! Ano passado eu viajei, de vez em quando eu vou para o sítio da minha colega. Quando eu quero, peço para alguém ficar com ela. Mando minha irmã vir e ficar com ela. E eu vou, passo o domingo, de tarde venho embora (GMS., 71 anos, irmã cuida da idosa há quatro meses, Manaus).

Afastar-se momentaneamente da situação de cuidados diminui o estresse. Alguns cuidadores referiram que precisaram superar suas apreensões de deixar o idoso com outras pessoas. A partir daí, se organizaram para ter alguns momentos de descanso sem se sentirem culpados. Entretanto, existem dinâmicas familiares que inviabilizam a alternância no cuidado ${ }^{11,17,19,20}$, seja pelo distanciamento e tensões pré-existentes no relacionamento dos familiares; a falta de comprometimento dos componentes familiares para o cuidar; distâncias geográficas, muitos filhos, especialmente no nordeste, em que várias famílias migraram para outras cidades, o que dificulta oferecer suporte aos cuidadores familiares. Salienta-se que, embora, 46,2\% dos participantes referiram que possuem ajuda para o cuidado, esse apoio só acontece aos finais de semana e de modo pontual, apenas em quatro famílias o cuidado é exercido em formato de plantão e efetivo revezamento entre os irmãos.

Vários cuidadores mencionaram que buscam aprender sobre os problemas de saúde dos entes dos quais cuidam, o que os torna seguros e confiantes no desempenho de sua função:

Para entender a doença dele eu conversei muito com os médicos e, também com a psicóloga lá do hospital onde ele foi internado, ela me orientou várias maneiras para lidar com ele. O programa do médico em casa [Melhor em casa] é fantástico, muito bom e o idoso ele se sente acolhido e tem orientações que nem familiar sabia e que a gente aprende dia a dia com o médico, com fisioterapeuta, enfermeiras, é um respaldo pra família muito significativo (LMP, 58 anos, filha cuida do pai há cinco meses, Porto Alegre).

Após o diagnóstico, conhecer e aprender sobre as nuances da doença, uma vez que algumas patologias demarcam comprometimentos significativos, afetando a parte motora, comportamental e afetiva da pessoa idosa e o seu relacionamento com o cuidador familiar, pode favorecer uma adaptação para que no exercício do cuidado seja minimizado o desgaste e a exaustão. É unânime entre os participantes deste estudo a necessidade do atendimento em geriatria e gerontologia. Iniciativas como o Programa Melhor em Casa com atendimento domiciliar aos idosos que requerem cuidados de longa duração são vistas como apoio necessário aos cuidadores familiares. Belo Horizonte possui o Programa Maior Cuidado que disponibiliza cuidadores formais para pessoas de baixa renda: não tenho condições físicas de cuidar dela, ter as meninas aqui em casa é uma benção, elas dão banho, fazem exercícios e interagem com a idosa, são só duas horas por dia, mas já ajuda (MJS, 60 anos, cuida da mãe acamada há quatro anos, Belo Horizonte).

A transição para o papel de cuidador precisa ser compreendida (e apoiada) de várias maneiras. Existe um tempo para o aprendizado do cuidar, que pode envolver o desenvolvimento de estraté- 
gias de manejo de aspectos clínicos, psicológicos e relacionais, expressos no dia a dia. Além de diversas orientações que podem ser generalizadas, existem necessidades emocionais e interpessoais que se impõem no relacionamento, provimento de apoio de outras pessoas e, quase sempre, de suporte social, financeiro e estrutural ${ }^{31}$.

Cuidadores familiares em todos os municípios fazem sacrifícios financeiros para ter um plano de saúde e garantir o atendimento especializado em geriatria. Os familiares também bancam fonoaudiólogos e fisioterapeutas particulares. Cuidadores formais de idosos são contratados quando o familiar não tem condições de cuidar 24horas/dia por não ter flexibilidade no ambiente de trabalho, ou uma pessoa para compartilhar o cuidado e não possuir condições físicas de cuidar do idoso.

Todo mundo gosta dela, os irmãos se reuniram para pagar cuidadora e enfermeira para cuidar dela direto, eu fico só acompanhando porque não tenho forças para cuidar. Acho que ela deve se sentir melhor aqui do que lá no hospital, sempre tem os irmãos que a visitam, eu passo a mão na cabeça dela e converso com ela (MHSM, 85 anos, cuida da filha com sequela de AVC há oito meses, Teresina)

A realidade brasileira é marcada por intensas desigualdades sociais, são poucos os familiares que conseguem se organizar financeiramente para ofertar o melhor cuidado ao idoso. Nesta pesquisa, apenas um pequeno número de cuidadores familiares cuidou de si, valorizando seus próprios afetos, com possibilidade de uma produção singular de ocupar seus lugares no mundo ao estabelecer uma rotina de cuidados eficaz.

Para Foucault ${ }^{32}$, a noção do cuidado de si evidencia a ética em si mesmo, em que o cuidado de si pode ser caracterizado como uma elaboração do sujeito por meio de uma transformação subjetiva e da consequente constituição de novos modos de vida, que se manifestam, pelos atos e condutas e por um conjunto de práticas e técnicas que são exercidas de si para consigo mesmo.

A prática de atividade física, a religião e a espiritualidade foram frequentemente descritas como meios de cuidado de si:

Eu faço minha atividade física todo dia. A parte espiritual, também é fundamental. É tão importante quanto o alimento material, então não deixo de ir para a igreja, eu sou ministra da eucaristia, uma vez na semana eu tenho que atender algumas pessoas, e graças a Deus eu posso fazer isso, e estou conseguindo conciliar (MCMAM, 59 anos, cuida do esposo há seis meses, Teresina)
Muitos cuidadores fazem orações, vão à igreja, recebem grupos religiosos em suas residências, em busca de forças para ajudar a suportar os dias difíceis. Para muitos, a fé é um mecanismo para aliviar as tensões. As convicções religiosas e as crenças relacionadas à fé foram consideradas particularmente positivas para as cuidadoras, dando-lhes significado para as tarefas do cuidar. Segundo a literatura, os cuidadores de cultura latina tendem a valorizar a religiosidade como apoio para o enfrentamento dos procedimentos de cuidado $^{11,22}$.

Como limitação do estudo aponta-se a falta de registro de cuidadores familiares no sistema de informação de saúde, o que fez com que a amostra fosse por conveniência.

\section{Considerações finais}

As dimensões empíricas que compõem as vivências de cuidadores familiares de idosos apontam que o cuidar é um trabalho eminentemente feminino e não remunerado. Chama-se atenção para o número de homens jovens cuidando dos idosos, e o não questionamento sobre o papel de cuidar entre os entrevistados. Assumir o papel de cuidador, para a maioria, envolveu sentimentos positivos, de gratidão, de responsabilidade ética e moral para com os parentes idosos que perderam sua autonomia. Há um senso de reciprocidade do cuidado recebido, em um movimento de renúncia de si mesmo em um código moral preestabelecido que vincula o sujeito no cuidado do outro.

As necessidades cotidianas dos cuidadores familiares se pautam pela insegurança por falta de orientação no atendimento em geriatria e gerontologia; repercussões psicossociais pelo trabalho penoso e repetitivo; privação social; dificuldades em conciliar cuidado e trabalho; suspensão da vida profissional e embaraços financeiros. Chamou atenção o percentual de pessoas idosas cuidando de idosos. Esse dado é preocupante devido ao aumento da vulnerabilidade dos cuidadores idosos frente à carga de trabalho rotineira e permanente.

É preciso chamar atenção do Estado brasileiro para a situação das pessoas que cuidam. Apesar da legislação brasileira considerar que o cuidado ao idoso dependente é uma atribuição da família, do estado e da sociedade civil, as políticas específicas que apoiem os cuidadores familiares são frágeis ou inexistem. Não há no país investimento financeiro direcionado ao cuidador familiar. Estudos que considerem a experiência 
dos cuidadores familiares pode ser um caminho para integrá-los como parte do sistema de saúde, valorizando suas demandas e garantir-lhes direitos e efetiva proteção do Estado.

\section{Colaboradores}

GS Sousa, RM Silva, DMD Gutierrez e MLF Figueiredo participaram da concepção do tema do artigo, coleta dos dados, análise e interpretação dos indicadores e elaboração do texto. AMS Reinaldo e SM Soares participaram da redação do artigo. Todos os autores realizaram revisão crítica e aprovação da versão final do escrito.

\section{Referências}

1. World Health Organization (WHO). Definition of an older or elderly person. Geneva: WHO; 2015

2. Anjos KF, Boery RNSO, Pereira R. Quality of life of relative caregivers of elderly dependents at home. Texto Contexto - Enferm 2014; 23(3):600-608.

3. Minayo MCS. O imperativo de cuidar da pessoa idosa dependente. Cien Saude Colet 2019; 24(1):247-252.

4. Frericks P, Jensen PH, Pfau-Effinger B. Social rights and employment rights related to family care: Family care regimes in Europe. Journal of Aging Studies 2014; 29(2):66-77.

5. Bass DM, Judge KS, Snow AL, Wilson NL, Looman WJ, McCarthy C, Morgan R, Ablorh-Odjidja C, Kunik ME. Negative caregiving effects among caregivers of veterans with dementia. Am J Geriatr Psychiatry 2012; 20(3):239-247.

6. Longacre ML, Valdmanis VG, Handorf, EA, Fang, CY. Work impact and emotional stress among informal caregivers for older adults. J Gerontol B Psychol Sci Soc Sci 2016; 72(3):522-531.

7. Connors MH, Seeher K, Teixeira-Pinto A, Woodward M., Ames D, Brodaty H. Mild cognitive impairment and caregiver burden: A 3-year-longitudinal study. Am J Geriatr Psychiatry 2019; 27(11):1206-1215.

8. McGilton KS, Vellani S, Yeung L, Chishtie J, Commisso E, Ploeg J. et al. Identifying and understanding the health and social care needs of older adults with multiple chronic conditions and their caregivers: a scoping review. BMC Geriatrics 2018; 18(1):e231.

9. Fernandez ML, Frías OA, Moreno CS, Palomino MPA, Del-Pino-Casado R. The start of caring for an elderly dependent family member: a qualitative metasynthesis. BMC Geriatrics 2018; 18(1):e228.

10. Kuluski K, Peckham A, Gill A, Arneja J, Morton-Chang F, Parsons J, Wong-Cornall C, McKillop A, Upshur REG, Sheridan N. "You've got to look after yourself, to be able to look after them" a qualitative study of the unmet needs of caregivers of community based primary health care patients. BMC Geriatrics 2018; 18(1):e275.

11. Mendez-Luck CA, Anthony KP, Guerrero LR. Burden and bad days among mexican-origin women caregivers. J Gerontol B Psychol Sci Soc Sci 2019; 75(8):17191730.

12. Mendonça JMB. Idosos no Brasil: políticas e cuidados. Brasília: Editora Juruá; 2016. 
13. Oxfam. Relatório sobre nós e a desigualdade "tempo de cuidar". Fórum Econômico Mundial de 2020, Davos. [acessado 2020 Jan 31]. Disponível em: https://oxfam. org.br/justica-social-e-economica/forum-economico-de-davos/tempo-de-cuidar/

14. Unión Europea (UE). Consejo de Europa. Recomendación 1591. Retos de la política social en las sociedades europeas que envejecen. Bruxelas: UE; 2003.

15. Minayo MCS. O desafio do conhecimento: pesquisa qualitativa em saúde. 14a ed. Rio de Janeiro: Hucitec; 2014.

16. Tamdee D, Tamdee P, Greiner C, Boochiang W, Okamoto N, Isowa T. Conditions of caring for the elderly and family caregiver stress in Chiang Mai, Thailand. Journal of Health Research 2019; 33(2):138-150.

17. Greenwood N, Smith R. Motivations for being informal carers of people living with dementia: a systematic review of qualitative literature. BMC Geriatrics 2019; 19(1):e169.

18. Pereira RM, Morales AR, Ferrada SC, Cuervo SC, Silva SMC, Díaz SC. Mayores cuidando mayores: sus percepciones desde una mirada integral. Enfermería: Cuidados Humanizados 2018; 7(2):83-108.

19. Karsch UM. Idosos dependentes: famílias e cuidadores. Cad Saude Publica 2003, 19(3):861-866.

20. Rodriguez P. El apoyo informal en la provisión de cuidados a las personas con dependencias. Madrid: Forum de políticas feministas; 2004.

21. European Association Working For Carers. Carers in Europe. [acessado 2020 Fev 23]. Disponível em: http://www.eurocarers.org/userfiles/file/Factsheet 2009.pdf

22. Losada A, Márquez-González M, Knight BG, Yanguas J, Sayegh P, Romero-Moreno R. Psychosocia factors and caregivers' distress: effects of familism and dysfunctional thoughts. Aging Ment Health 2010; 14(2):193-202.

23. Couto AM, Caldas CP, Castro EAB. Family caregiver of older adults and cultural care in nursing care. Rev Bras Enferm, 2018; 71(3):959-966.

24. Special Senate Committee on Aging. Canada's Aging Population: Seizing the Opportunity. Final report. Otawa: 2009. [acessado 2020 Mar 6]. Disponível em: https://sencanada.ca/content/sen/Committee/402/ agei/rep/AgingFinalReport-e.pdf

25. Spasova S, Baeten R, Coster S, Ghailani D, Peña-Casas $\mathrm{R}$, Vanhercke B. Challenges in long-term care in Europe, a study of national policies. Brusssels: European Commission; 2018
26. Wolf PJW, Oliveira GC. Os Estados de Bem-Estar Social da Europa Ocidental: tipologias, evidências e vulnerabilidades. Economia e Sociedade 2016; 25(3):661694.

27. Langner LA, Furstenberg FF. Gender differences in spousal Caregivers' care and housework: fact or fiction? J Gerontol B Psychol Sci Soc Sci 2020; 75(1):173183.

28. Sayegh P, Knight BG. The effects of familism and cultural justification on the mental and physical health of family caregivers. J Gerontol B Psychol Sci Soc Sci 2010; 66B(1):3-14.

29. Heidegger M. Ser e tempo. 6a ed. Petrópolis: Vozes; 1997. Parte 1.

30. Organization of Economic Development (OCDE). Policies to support family cargivers. IV chapter. In: Organization of Economic Development (OCDE). Help wanted? Providing and paying for long term care. Paris: OCDE Publishing; 2011. p. 121-158.

31. Fernandes CS, Angelo M, Silva JAM, Carvalho BG. Family caregivers: what do they need? An integrative review. Revista da Escola de Enfermagem da USP 2016; 10 (4):675-682.

32. Foucault M. A hermenêutica do sujeito. São Paulo: Martins Fontes; 2010

Artigo apresentado em 26/05/2020

Aprovado em 19/08/2020

Versão final apresentada em 21/08/2020

Editores chefes: Maria Cecília de Souza Minayo, Romeu Gomes, Antônio Augusto Moura da Silva. Editora Associada da área de Saúde do Idoso: Joselia Oliveira Araújo Firmo 